\title{
The Regulation of the AdcR Regulon in Streptococcus pneumoniae Depends Both on $\mathrm{Zn}^{2+}$ - and $\mathrm{Ni}^{2+}$-Availability
}

\author{
Irfan Manzoor ${ }^{1,2 \dagger}$, Sulman Shafeeq ${ }^{1,3+}$, Muhammad Afzal ${ }^{1,2}$ and Oscar P. Kuipers ${ }^{1 *}$ \\ ${ }^{1}$ Department of Molecular Genetics, Groningen Biomolecular Sciences and Biotechnology Institute, University of Groningen, \\ Groningen, Netherlands, ${ }^{2}$ Department of Bioinformatics and Biotechnology, Government College University Faisalabad, \\ Faisalabad, Pakistan, ${ }^{3}$ Department of Microbiology, Tumor and Cell Biology, Karolinska Institutet, Stockholm, Sweden
}

OPEN ACCESS

Edited by:

Jorge Eugenio Vidal,

Emory University, USA

Reviewed by:

Hilde De Reuse,

Institut Pasteur, France

Stephen Peter Kidd,

University of Adelaide, Australia

*Correspondence:

Oscar P. Kuipers

o.p.kuipers@rug.nl

${ }^{\dagger}$ These authors have contributed equally to this work.

Received: 27 August 2015 Accepted: 17 November 2015 Published: 08 December 2015

Citation:

Manzoor I, Shafeeq S, Afzal M and Kuipers OP (2015) The Regulation of the AdcR Regulon in Streptococcus pneumoniae Depends Both on $\mathrm{Zn}^{2+}$. and $\mathrm{Ni}^{2+}$-Availability.

Front. Cell. Infect. Microbiol. 5:91. doi: 10.3389/fcimb.2015.00091
By using a transcriptomic approach, we have elucidated the effect of $\mathrm{Ni}^{2+}$ on the global gene expression of $S$. pneumoniae D39 by identifying several differentially expressed genes/operons in the presence of a high extracellular concentration of $\mathrm{Ni}^{2+}$. The genes belonging to the AdcR regulon (adcRCBA, adcAll-phtD, phtA, phtB, and phtE) and the PsaR regulon ( $p c p A$, prtA, and $p s a B C A$ ) were highly upregulated in the presence of $\mathrm{Ni}^{2+}$. We have further studied the role of $\mathrm{Ni}^{2+}$ in the regulation of the AdcR regulon by using ICP-MS analysis, electrophoretic mobility shift assays and transcriptional lacZ-reporter studies, and demonstrate that $\mathrm{Ni}^{2+}$ is directly involved in the derepression of the AdcR regulon via the $\mathrm{Zn}^{2+}$-dependent repressor $\mathrm{AdcR}$, and has an opposite effect on the expression of the AdcR regulon compared to $\mathrm{Zn}^{2+}$.

Keywords: metal homeostasis, pneumococcus, nickel, zinc, AdcR, Pht family proteins, AdcR regulon, PsaR regulon

\section{INTRODUCTION}

In bacteria, the transition metal ions play an important role in the proper functioning of many enzymes, transporters, and transcriptional regulators. Transition metal ions are the prerequisite for the proper bacterial growth at low concentrations, but metal ions can be lethal at higher concentrations (Blencowe and Morby, 2003; Finney and O'Halloran, 2003; Moore and Helmann, 2005; Ge et al., 2012). Therefore, proper homeostasis of metal ions is very important for the survival of bacteria, which is maintained by the dedicated metal transport- and efflux-systems (Tottey et al., 2008; Waldron and Robinson, 2009; Lisher et al., 2013). These systems are tightly regulated by metal-responsive transcriptional regulators to ensure the proper functioning of the cell by maintaining the minimum levels of metal ions inside the cell.

Streptococcus pneumoniae is one of the most common human pathogens that reside asymptomatically in the human nasopharynx (Mitchell, 2003). However, it may occasionally translocate to the lungs, the eustachian tube, the blood, and the nervous system, causing pneumoniae, otitis media, bacteremia, and meningitis, respectively (Obaro and Adegbola, 2002; Bogaert et al., 2004). During translocation from the nasopharynx to other infection sites, $S$. pneumoniae may encounter different environmental conditions including varying metal ions concentrations, which might affect the expression of different genes including virulence genes (Gupta et al., 2009; Shafeeq et al., 2011b, 2013; Plumptre et al., 2014a). However, the exact conditions that $S$. pneumoniae might face during infections, are poorly understood. 
The role of manganese $\left(\mathrm{Mn}^{2+}\right)$, zinc $\left(\mathrm{Zn}^{2+}\right)$, copper $\left(\mathrm{Cu}^{2+}\right)$, iron $\left(\mathrm{Fe}^{2+}\right)$, cobalt $\left(\mathrm{Co}^{2+}\right)$, and cadmium $\left(\mathrm{Cd}^{2+}\right)$ on the gene regulation of $S$. pneumoniae have already been established and several metal-specific acquisition- and efflux-systems have been characterized. These systems include AdcRCBA (the $\mathrm{Zn}^{2+}$ uptake system), $\mathrm{CzcD}$ (the $\mathrm{Zn}^{2+}$-efflux system), PsaBCA (the $\mathrm{Mn}^{2+}$-uptake system), MntE (the $\mathrm{Mn}^{2+}$-efflux system), the cop operon (the $\mathrm{Cu}^{2+}$-efflux system), and PiaABCD, PiuBCDA, and PitADBC (the $\mathrm{Fe}^{2+}$ - and $\mathrm{Fe}^{3+}$-uptake systems) (Kloosterman et al., 2007, 2008; Hendriksen et al., 2009; Rosch et al., 2009; Bayle et al., 2011; Shafeeq et al., 2011a, 2013; Manzoor et al., 2015c). These systems have further been shown to be regulated by metal-specific transcriptional regulators in S. pneumoniae. The $\mathrm{Zn}^{2+}$-uptake system (AdcRCBA) is repressed by transcriptional regulator AdcR in the presence of $\mathrm{Zn}^{2+}$ (Shafeeq et al., 2011a). Similarly, the $p s a B C A$ operon encoding $\mathrm{Mn}^{2+}$-uptake system are repressed by transcriptional regulator PsaR in the presence of $\mathrm{Mn}^{2+}$ (Johnston et al., 2006; Kloosterman et al., 2008), whereas, this PsaR-mediated repression is relieved by the addition of $\mathrm{Zn}^{2+}$, $\mathrm{Co}^{2+}, \mathrm{Cd}^{2+}$, or $\mathrm{Ni}^{2+}$ (Kloosterman et al., 2008; Jacobsen et al., 2011; Begg et al., 2015; Manzoor et al., 2015a,b,c).

$\mathrm{Ni}^{2+}$ is an essential micronutrient for certain bacteria, due to its role in various cellular processes like methane formation, hydrolysis of urea, and consumption of molecular hydrogen (Chen and Burne, 2003; Mulrooney and Hausinger, 2003; Rodionov et al., 2006; Anwar et al., 2007). In Escherichia coli, the nik operon (nikABCDE) involved in the transport of $\mathrm{Ni}^{2+}$ is shown to regulate by transcriptional regulator NikR (De Pina et al., 1999). Moreover, the expression of NmtA, an ATPdependent transporter involved in the efflux of $\mathrm{Ni}^{2+}$ and $\mathrm{Co}^{2+}$, is tightly regulated by $\mathrm{Ni}^{2+}$-responsive transcriptional regulator NmtR in Mycobacterium tuberculosis (Cavet et al., 2002). $\mathrm{Ni}^{2+}$ is also shown to regulate the expression of urease activity in Streptococcus salivarius and Helicobacter pylori (van Vliet et al., 2001; Chen and Burne, 2003). The amount of $\mathrm{Ni}^{2+}$ in the human blood is estimated to be $0.83 \mathrm{ng} \mathrm{ml}^{-1}$ (Alimonti et al., 2005) and it is likely that $S$. pneumoniae may encounter $\mathrm{Ni}^{2+}$ during infection in blood. So far, very little is known about the impact of $\mathrm{Ni}^{2+}$ on the global gene expression of S. pneumoniae. Previously, the role of $\mathrm{Ni}^{2+}$ in the regulation of the $\mathrm{Zn}^{2+}$-efflux system $c z c D$ was reported (Kloosterman et al., 2007). It was shown that the SczA-mediated expression of $c z c D$ was highly increased in the presence of $\mathrm{Zn}^{2+}, \mathrm{Co}^{2+}$, or $\mathrm{Ni}^{2+}$ (Kloosterman et al., 2007). Moreover, a number of proteins and motif with $\mathrm{Co}^{2+}$ - and $\mathrm{Ni}^{2+}$-binding capacity has been identified by Immobilized metal affinity column (IMAC) and LTQ-Orbitrap mass spectrometry (MS) that have diverse functions in the S. pneumoniae (Sun et al., 2013). In a recent study, we demonstrated the role of $\mathrm{Ni}^{2+}$ in regulation of the PsaR regulon and showed that $\mathrm{Ni}^{2+}$ not only alleviates the $\mathrm{Mn}^{2+}$-dependent binding of $\mathrm{PsaR}$ to the promoter regions of the PsaR regulon genes, but also cause $\mathrm{Mn}^{2+}$ deficiency possibly by blocking $\mathrm{Mn}^{2+}$-uptake via PsaA, hence leading to the high expression of the PsaR regulon in the presence of $\mathrm{Ni}^{2+}$ (Manzoor et al., 2015b).

In this current study, we used a transcriptomic analysis approach for the identification of differentially expressed genes/operons in response to high extracellular $\mathrm{Ni}^{2+}$ in $S$. pneumoniae. The expression of genes belonging to the AdcR regulon and the PsaR regulon was highly upregulated in the presence of $\mathrm{Ni}^{2+}$. We further studied the role of $\mathrm{Ni}^{2+}$ in the AdcR-mediated regulation of the adcRCBA, adcAII-phtD, $p h t A$, phtB, and $p h t E$ by using transcriptional lacZ-reporter studies, inductively coupled plasma-mass spectrometry (ICPMS) analysis and electrophoretic mobility shift assays (EMSAs), and showed that $\mathrm{Ni}^{2+}$ and $\mathrm{Zn}^{2+}$ play an opposite role in

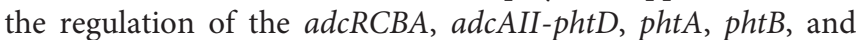
phtE.

\section{MATERIALS AND METHODS}

\section{Bacterial Strains and Media}

Bacterial strains used in this study are listed in Table 1. Growth of bacteria and DNA manipulation were performed as described (Shafeeq et al., 2011a; Manzoor et al., 2015a). All experiments in this study were performed in chemically defined medium (CDM).

TABLE 1 | List of strains and plasmids used in this study.

\begin{tabular}{|c|c|c|}
\hline Strain/plasmid & Description & Source \\
\hline \multicolumn{3}{|l|}{ S. pneumoniae } \\
\hline D39 & Serotype 2 strain, cps 2 & Laboratory of P. Hermans \\
\hline SS200 & D39 $\Delta$ adcR; Ery ${ }^{R}$ & Shafeeq et al., 2011a \\
\hline IM404 & D39 $\triangle$ bgaA::PczcD-lacZ; Tet $^{R}$ & Manzoor et al., 2015a \\
\hline IM501 & D39 $\Delta$ bgaA::PadcR-lacZ; Tet ${ }^{R}$ & This study \\
\hline IM502 & D39 $\Delta$ bgaA::PadcAll-lacZ; Tet ${ }^{R}$ & This study \\
\hline IM503 & D39 $\Delta$ bgaA::PphtA-lacZ; Tet ${ }^{\mathrm{R}}$ & This study \\
\hline IM504 & D39 $\Delta$ bgaA::PphtB-lacZ; Tet ${ }^{R}$ & This study \\
\hline IM505 & D39 $\Delta$ bgaA::PphtE-lacZ; Tet ${ }^{R}$ & This study \\
\hline IM551 & $\begin{array}{l}\text { SS200 } \Delta b g a A:: P a d c R-l a c Z ; \\
\text { Tet }^{R}\end{array}$ & This study \\
\hline IM552 & $\begin{array}{l}\text { SS200 } \Delta b g a A:: P a d c A l l-l a c Z ; \\
\text { Tet }^{R}\end{array}$ & This study \\
\hline IM553 & SS200 $\Delta$ bgaA::PphtA-lacZ; Tet ${ }^{R}$ & This study \\
\hline IM554 & SS200 $\Delta$ bgaA::PphtB-lacZ; Tet ${ }^{R}$ & This study \\
\hline IM555 & SS200 $\Delta$ bgaA::PphtE-lacZ; Tet ${ }^{R}$ & This study \\
\hline \multicolumn{3}{|l|}{ E. coli } \\
\hline EC1000 & $\begin{array}{l}\mathrm{Km} \mathrm{R}^{\mathrm{R}} \text { MC1000 derivative } \\
\text { carrying a single copy of the } \\
\text { pWV1 repA gene in glgB }\end{array}$ & Laboratory collection \\
\hline \multicolumn{3}{|l|}{ Plasmids } \\
\hline pPP2 & $\begin{array}{l}\text { Amp }^{R} \text { Tet }^{R} \text {; promoterless lac } Z \\
\text { For replacement of bgaA with } \\
\text { promoter lacZ-fusion. Derivative } \\
\text { of pPP1 }\end{array}$ & Halfmann et al., 2007 \\
\hline plM501 & pPP2 PadcR-lacZ & This study \\
\hline plM502 & pPP2 PadcAll-lacZ & This study \\
\hline plM503 & pPP2 PphtA-lacZ & This study \\
\hline plM504 & pPP2 PphtB-lacZ & This study \\
\hline plM505 & pPP2 PphtE-lacZ & This study \\
\hline SS107 & $\begin{array}{l}\text { pNZ8048 carrying strep-tagged } \\
\text { AdcR downstream of PnisA }\end{array}$ & Shafeeq et al., 2011a \\
\hline
\end{tabular}


TABLE 2 | List of primers used in this study.

\begin{tabular}{|c|c|c|}
\hline Name & Nucleotide sequence $\left(5^{\prime} \rightarrow 3^{\prime}\right)$ & $\begin{array}{l}\text { Restriction } \\
\text { site }\end{array}$ \\
\hline Padcr-F & CGGAATTCTIITCAGCAAAGATTGGG & EcoRl \\
\hline Padcr-R & CGGGATCCCTTCCTTTAAGACTTCTC & BamHI \\
\hline PadcAll-F & CGGAATTCCTTCACTTATGGCTATAAGC & EcoRl \\
\hline PadcAll-R & CGGGATCCAAAGAAAGACACTTAACAGG & BamHI \\
\hline PphtA-F & CGGAATTCTGAACTTCAAAAAGAATACG & EcoRl \\
\hline PphtA-R & CGGGATCCCTTAAAATCAAAGCTGCCGC & $\mathrm{BamHI}$ \\
\hline PphtB-F & GCATGAATTCGGCAGAAGCAGAAAAATTAC & EcoRl \\
\hline PphtB-R & CGATGGATCCAAGTGTAGCTACTGACC & $\mathrm{BamHI}$ \\
\hline PphtE-F & CGGAATTCAGAAGTAGATAGTCTCTTGG & EcoRI \\
\hline PphtE-R & CGGGATCCACGATAACAGCTGATCCAGC & BamHI \\
\hline
\end{tabular}

Salts of metal ion $\mathrm{ZnSO}_{4} \cdot 7 \mathrm{H}_{2} \mathrm{O}$ and $\mathrm{NiSO}_{4} \cdot 6 \mathrm{H}_{2} \mathrm{O}$ were used as specified in the Results section. Primers used in this study are based on the genome sequence of S. pneumoniae D39 and are listed in Table 2.

\section{DNA Microarray and Data Analysis}

For microarray analysis in response to $\mathrm{Ni}^{2+}$, S. pneumoniae D39 wild-type was grown in two biological replicates in CDM with and without the addition of $0.5 \mathrm{mM} \mathrm{NiSO}_{4} 6 \mathrm{H}_{2} \mathrm{O}$. To analyze the impact of $a d c R$ deletion on the transcirptome of $S$. pneumoniae in the presence of $\mathrm{Ni}^{2+}, \mathrm{D} 39$ wild-type and $\triangle a d c R$ (SS200) (Shafeeq et al., 2011a) were grown in two biological replicates in $\mathrm{CDM}$ with $0.3 \mathrm{mM}$ of $\mathrm{NiSO}_{4} 6 \mathrm{H}_{2} \mathrm{O}$. All other procedures regarding microarray experiments and data analysis were done as described before (Shafeeq et al., 2011b; Afzal et al., 2015). For the identification of differentially expressed genes a Bayesian $p<0.001$ and a fold change cut-off of 2 was applied. The DNA microarray data have been submitted to gene expression omnibus (GEO) database under the accession number GSE73852.

\section{Construction of Transcriptional lacZ-fusions and $\beta$-galactosidase Assays}

Chromosomal transcriptional lacZ-fusions to the promoter regions of $a d c R, a d c A I I$, pht $A$, phtB, and $p h t E$ were constructed in plasmid pPP2 (Halfmann et al., 2007) with the primer pairs listed in Table 2, resulting in pIM501-505. These plasmids were introduced into D39 wild-type and $\triangle a d c R$ (SS200) (Shafeeq et al., 2011a) resulting in strains IM501-505 and IM551-554, respectively. All plasmids were checked for the presence of correct insert by means of PCR and DNA sequencing. For $\beta$ galactosidase activity, the derivatives of $S$. pneumoniae were grown in triplicate in CDM supplemented with different metal ion concentrations (w/v) mentioned in the Results and harvested at the mid-exponential growth phase. The $\beta$-galactosidase activity was measured as described before (Kloosterman et al., 2006). Standard deviations were calculated from three independent replicates of each sample.

\section{Inductively Coupled Plasma-mass Spectrometry (ICP-MS) Analysis}

To determine the cell-associated concentration of metal ions, an ICP-MS analysis was performed on the cells grown in triplicates in $\mathrm{CDM}$ with and without the addition of $0.5 \mathrm{mM} \mathrm{Ni}^{2+}$ till the mid-exponential growth phase. Cell cultures were centrifuged at $4^{\circ} \mathrm{C}$ and washed twice with overnight Chelex (Sigma) treated phosphate-buffered saline (PBS) with $1 \mathrm{mM}$ nitrilotriacetic acid. Cells were dried overnight in a Speedvac at room temperature. The dried cells were dissolved in $2.5 \%$ nitric acid (Ultrapure, Sigma Aldrich) and lysed at $95^{\circ} \mathrm{C}$ for $10 \mathrm{~min}$ by vigorous vortexing after each $30 \mathrm{~s}$. The lysed cell samples were used for ICP-MS analysis as described (Jacobsen et al., 2011). Metal ion concentrations were expressed as $\mu \mathrm{g} \mathrm{g}^{-1}$ dry weight of cells.

\section{Overexpression and Purification of Strep-tagged AdcR}

The nisin-inducible (NICE) expression system (Kuipers et al., 1998) in Lactococcus lactis strain NZ9000 was used for the overexpression of C-terminally Strep-tagged AdcR (Shafeeq et al., 2011a). Cells were grown until an $\mathrm{OD}_{600}$ of 0.4 in $1 \mathrm{~L}$ culture followed by the induction with $10 \mathrm{ng} \mathrm{ml}^{-1}$ nisin. The purification of AdcR-Strep tag was performed using the Streptactin column from IBA according to the supplier's instructions (www.iba-go.com). The purified protein was eluted in buffers without EDTA and stored at a concentration of $0.5 \mathrm{mg} / \mathrm{ml}$ in the elution buffer (100 mM Tris- $\mathrm{HCl}$ [pH 8], $150 \mathrm{mM} \mathrm{NaCl}, 2.5 \mathrm{mM}$ desthiobiotin, and $1 \mathrm{mM} \beta$-mercaptoethanol) with $10 \%$ glycerol at $-80^{\circ} \mathrm{C}$.

\section{Electrophoretic Mobility Shift Assays}

Electrophoretic mobility shift assays (EMSAs) were performed as described (Kloosterman et al., 2008). In short, PCR products of the promoter regions of $a d c R, a d c A I I$, pht $A$, phtB, and $p c p A$ were labeled with $\left[\gamma_{-}{ }^{33} \mathrm{P}\right]$ ATP. All the EMSAs were performed with $5000 \mathrm{cpm}$ of $\left[\gamma^{-33} \mathrm{P}\right]$ ATP-labeled PCR products in buffer containing $20 \mathrm{mM}$ Tris-HCL ( $\mathrm{pH} 8.0$ ), $5 \mathrm{mM} \mathrm{MgCl}_{2}, 8.7 \%$ (w/v) glycerol, $62.5 \mathrm{mM} \mathrm{KCl}, 25 \mu \mathrm{g} / \mathrm{ml}$ bovine serum albumin and $25 \mu \mathrm{g} / \mathrm{ml}$ poly (dI-dC). Various metal ions were added in concentrations as described in the Results section. Reactions were incubated at $30^{\circ} \mathrm{C}$ for $30 \mathrm{~min}$ before loading on gels. Gels were run in $1 \mathrm{M}$ Tris-borate buffer ( $\mathrm{pH} \mathrm{8.3)} \mathrm{at} 95 \mathrm{~V}$ for $90 \mathrm{~min}$.

\section{RESULTS}

\section{Identification of $\mathrm{Ni}^{2+}$-dependent Genes in S. pneumoniae}

To investigate the impact of $\mathrm{Ni}^{2+}$ on the transcriptome of $S$. pneumoniae, a DNA microarray-based comparison of D39 wildtype grown in CDM with $0.5 \mathrm{mM} \mathrm{Ni}^{2+}$ to the same strain grown in CDM with $0 \mathrm{mM} \mathrm{Ni}^{2+}$ was performed. Table 3 summarizes the list of differentially expressed genes in the presence of $0.5 \mathrm{mM} \mathrm{Ni}^{2+}$. The PsaR regulon consisting of the operon $p s a B C A$ (encoding $\mathrm{Mn}^{2+}$-dependent $\mathrm{ABC}$ transporters, PsaBCA), $p c p A$ (encoding a choline binding protein, PcpA), and prtA (encoding a serine protease PrtA) were highly upregulated in the presence of 
TABLE 3 | Summary of transcriptome comparison of S. pneumoniae D39 wild-type grown in CDM plus $0.5 \mathrm{mM} \mathrm{Ni}^{2+}$ to CDM plus $0 \mathrm{mM} \mathrm{Ni}^{2+}$.

\begin{tabular}{|c|c|c|c|}
\hline Gene tag ${ }^{a}$ & Function $^{b}$ & Ratio $^{c}$ & $P$-value \\
\hline SPD0475 & $\begin{array}{l}\text { CAAX amino terminal protease family } \\
\text { protein }\end{array}$ & 5.39 & $1.48 \mathrm{E}-11$ \\
\hline SPD0526 & $\begin{array}{l}\text { Fructose-1,6-bisphosphate aldolase, } \\
\text { class II }\end{array}$ & 3.07 & $1.93 \mathrm{E}-13$ \\
\hline SPD0558 & Cell wall-associated serine protease, PrtA & 9.67 & $2.92 \mathrm{E}-13$ \\
\hline SPD0738 & Cytidine deaminase & 21.92 & $6.05 \mathrm{E}-07$ \\
\hline SPD0888 & Adhesion lipoprotein, AdcAll (LmB) & 2.07 & $7.08 \mathrm{E}-07$ \\
\hline SPD0889 & $\begin{array}{l}\text { Pneumococcal histidine triad protein } \\
\text { D, PhtD }\end{array}$ & 2.06 & $5.81 \mathrm{E}-10$ \\
\hline SPD0890 & $\begin{array}{l}\text { Pneumococcal histidine triad protein } \\
\text { E, PhtE }\end{array}$ & 7.13 & $2.81 \mathrm{E}-05$ \\
\hline SPD1038 & $\begin{array}{l}\text { Pneumococcal histidine triad protein } \\
\text { A, PhtA }\end{array}$ & 12.54 & $2.00 \mathrm{E}-14$ \\
\hline SPD1078 & L-lactate dehydrogenase & 4.21 & $2.04 \mathrm{E}-14$ \\
\hline SPD1138 & Heat shock protein, $\mathrm{HtpX}$ & 3.61 & $9.44 \mathrm{E}-05$ \\
\hline SPD1360 & Hypothetical protein & 7.29 & $1.15 \mathrm{E}-10$ \\
\hline SPD1402 & Non-heme iron-containing ferritin, DpR & 2.65 & $2.10 \mathrm{E}-11$ \\
\hline SPD1461 & $\begin{array}{l}\text { Manganese ABC transporter, ATP-binding } \\
\text { protein, PsaB }\end{array}$ & 11.90 & 5.33E-15 \\
\hline SPD1462 & $\begin{array}{l}\text { Manganese } A B C \text { transporter, permease } \\
\text { protein, PsaC }\end{array}$ & 10.71 & $5.26 \mathrm{E}-14$ \\
\hline SPD1464 & Thiol peroxidase & 2.13 & $8.68 \mathrm{E}-10$ \\
\hline SPD1632 & Hypothetical protein & 2.32 & 3.47E-05 \\
\hline SPD1633 & $\begin{array}{l}\text { Galactose-1-phosphate uridylyl } \\
\text { transferase, GalT }\end{array}$ & 2.68 & 7.81E-06 \\
\hline SPD1634 & Galactokinase, GalK & 4.13 & 1.29E-08 \\
\hline SPD1635 & Galactose operon repressor, GalR & 5.00 & 4.27E-07 \\
\hline SPD1636 & $\begin{array}{l}\text { Alcohol dehydrogenase, zinc-containing, } \\
\text { AdhB }\end{array}$ & 35.69 & $0.00 \mathrm{E}+00$ \\
\hline SPD1637 & Transcriptional regulator, MerR family & 38.25 & $0.00 \mathrm{E}+00$ \\
\hline SPD1638 & Cation efflux system protein, CzcD & 77.89 & $5.55 \mathrm{E}-15$ \\
\hline SPD1651 & $\begin{array}{l}\text { Iron-compound ABC transporter, } \\
\text { ATP-binding protein }\end{array}$ & -3.91 & $1.27 \mathrm{E}-13$ \\
\hline SPD1652 & $\begin{array}{l}\text { Iron-compound ABC transporter, } \\
\text { iron-compound-binding protein }\end{array}$ & -3.73 & 4.57E-12 \\
\hline SPD1965 & Choline binding protein, PcpA & 2.80 & 8.16E-04 \\
\hline SPD1997 & $\begin{array}{l}\text { Zinc ABC transporter, zinc-binding } \\
\text { lipoprotein, AdcA }\end{array}$ & 3.91 & 1.14E-12 \\
\hline SPD1998 & $\begin{array}{l}\text { Zinc ABC transporter, permease protein, } \\
\text { AdcB }\end{array}$ & 2.00 & 2.47E-04 \\
\hline SPD1999 & $\begin{array}{l}\text { Zinc ABC transporter, ATP-binding protein, } \\
\text { AdcC }\end{array}$ & 4.17 & $1.29 \mathrm{E}-13$ \\
\hline SPD2000 & adc operon repressor, AdcR & 3.88 & $2.46 \mathrm{E}-11$ \\
\hline
\end{tabular}

${ }^{a}$ Gene numbers refer to D39 locus tags.

${ }^{b}$ D39 annotation/TIGR4 annotation (Hoskins et al., 2001; Lanie et al., 2007).

${ }^{c}$ Ratios $>2.0$ or $<2.0$ (wild-type + $0.5 \mathrm{mM} \mathrm{Ni}^{2+}$ /wild-type + $\mathrm{mM} \mathrm{Ni}^{2+}$ ).

$\mathrm{Ni}^{2+}$. The $\mathrm{Ni}^{2+}$-dependent upregulation of the PsaR regulon in the presence of $\mathrm{Ni}^{2+}$ is consistent with our recent study, where we have explored the $\mathrm{Ni}^{2+}$-dependent regulation of the PsaR regulon in more details (Manzoor et al., 2015b). Expression of a gene cluster including the cation efflux system gene $c z c D$, the MerR family transcriptional regulator, and the $\mathrm{Zn}^{2+}$-containing alcohol dehydrogenase $a d h B$ was increased more than 35 -fold in

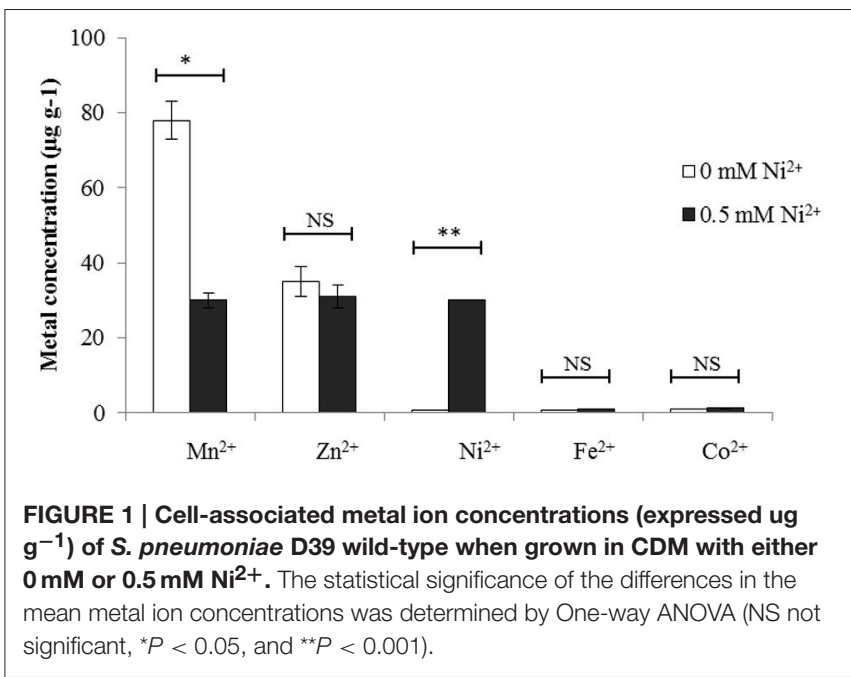

the presence of $\mathrm{Ni}^{2+}$. The cation efflux system $\mathrm{CzcD}$ was shown to protect $S$. pneumoniae against the intracellular $\mathrm{Zn}^{2+}$-stress (Kloosterman et al., 2007). A novel TetR family transcriptional regulator SczA has been shown to activate the expression of $c z c D$ in the presence of $\mathrm{Zn}^{2+}, \mathrm{Co}^{2+}$, or $\mathrm{Ni}^{2+}$ (Kloosterman et al., 2007). Therefore, the upregulation of $c z c D$ in our transcriptomic analysis is consistent with the finding presented in previous study (Kloosterman et al., 2007). Furthermore, genes encoding a heat shock protein (HtpX) and a Dpr homolog (spd_1402) were also differentially expressed. The Dpr protein has been shown to protect bacterial cells from oxidative stress (Pulliainen et al., 2003).

The genes belonging to the AdcR regulon were also upregulated in the presence of $\mathrm{Ni}^{2+}$. The expression of the $a d c$ operon was 4 -fold upregulated. The expression of adcAII$p h t D$ operon was upregulated 2 -fold. The expression of other genes encoding for Pht family proteins (PhtA and PhtE), was upregulated more then 7-fold. Previously, it was shown that the expression of the AdcR regulon is repressed by the transcriptional regulator AdcR in the presence of $\mathrm{Zn}^{2+}$ (Shafeeq et al., 2011a). Transcriptome data was further validated by qRT-PCR analysis (Supplementary data: Table S1). Upregulation of the AdcR regulon in the presence of $\mathrm{Ni}^{2+}$ might also indicate the putative role of $\mathrm{Ni}^{2+}$ in the regulation of the $\mathrm{AdcR}$ regulon by the transcriptional regulator AdcR. Therefore, we decided to further explore the role of $\mathrm{Ni}^{2+}$ in the regulation of the $\mathrm{AdcR}$ regulon and to determine the intracellular concentrations of metal ions in $S$. pneumoniae $\mathrm{D} 39$ grown in the presence of either $0.5 \mathrm{mM} \mathrm{Ni}^{2+}$ or $0 \mathrm{mM} \mathrm{Ni}^{2+}$ in CDM.

\section{S. pneumoniae Accumulates $\mathrm{More} \mathrm{Ni}^{2+}$ When Grown in the Presence of $0.5 \mathrm{mM}$ $\mathrm{Ni}^{2+}$}

To investigate whether the observed transcriptomic responses correlated with high cell-associated concentration of $\mathrm{Ni}^{2+}$, we performed an ICP-MS analysis on the same conditions used for performing the transcriptome analysis, i.e., cells grown either in the presence of $0.5 \mathrm{mM} \mathrm{Ni}^{2+}$ or $0 \mathrm{mM} \mathrm{Ni}^{2+}$ in CDM. Our 
ICP-MS data revealed that the cells grown in the presence of $0.5 \mathrm{mM} \mathrm{Ni}^{2+}$ accumulate 30 -fold more cell-associated $\mathrm{Ni}^{2+}$ compared to the cells grown in $0 \mathrm{mM} \mathrm{Ni}^{2+}\left(30 \mu \mathrm{g} \mathrm{g}^{-l}\right.$ dry mass of cells vs. $<1 \mu \mathrm{g} \mathrm{g}^{-l}$ dry mass of cells) (Figure 1). Moreover, 2.6fold decrease in the cell-associated concentration of $\mathrm{Mn}^{2+}$ was observed. The cell-associated concentration of other metal ions was not changed in the presence of $0.5 \mathrm{mM} \mathrm{Ni}^{2+}$ compared to $0 \mathrm{mM} \mathrm{Ni}^{2+}$. Therefore, it is likely that the transcriptomic changes observed in the presence of $0.5 \mathrm{M} \mathrm{Ni}^{2+}$ are due to the high intracellular concentration of $\mathrm{Ni}^{2+}$.

\section{$\mathrm{Ni}^{2+}$-dependent Expression of the AdcR}

\section{Regulon}

To explore the transcriptional regulation of the genes/operons belonging to the AdcR regulon (adcRCBA, adcAII-phtD, phtA, $p h t B$, and $p h t E$ ) found in our microarray analysis, transcriptional lac $Z$-fusions were constructed to the promoter regions of $a d c R$, adcAII, pht A, phtB, and phtE in plasmid pPP2 (Halfmann et al., 2007) and transferred to $S$. pneumoniae D39 wild-type. The expression of PadcR-lacZ, PadcAII-lacZ, PphtA-lacZ, PphtB-lacZ, and PphtE-lacZ was measured in CDM and CDM- $\mathrm{Zn}^{2+}\left(\mathrm{Zn}^{2+}\right.$ depleted medium) with the addition of $0,0.1,0.3$, or $0.5 \mathrm{mM}$ $\mathrm{Ni}^{2+}$. As AdcR represses the expression of the AdcR regulon in the presence of $\mathrm{Zn}^{2+}$, we also used $\mathrm{Zn}^{2+}$-depleted medium $\left(\mathrm{CDM}-\mathrm{Zn}^{2+}\right) . \beta$-galactosidase activity (Miller Units) showed that the elevated concentration of $\mathrm{Ni}^{2+}$ led to the high expression of all these promoters in CDM and CDM- $\mathrm{Zn}^{2+}$ (Figures 2A,B). However, the expression of these promoters was much higher in $\mathrm{CDM}-\mathrm{Zn}^{2+}$ compared to CDM. The full CDM contains minor amounts of $\mathrm{Zn}^{2+}$ (around $883 \mu \mathrm{g} \mathrm{l}^{-1}$ ) (Manzoor et al., 2015a), which could explain the lower expression of these promoters in CDM compared to CDM- $\mathrm{Zn}^{2+}$. This data not only suggests the role of $\mathrm{Ni}^{2+}$ in the regulation of the adcRCBA, adcAII-phtD, $p h t A, p h t B$, and $p h t E$, but also indicate the ability of $\mathrm{Ni}^{2+}$ to derepress the $\mathrm{Zn}^{2+}$-dependent repression of these genes.

\section{Opposite Effect of $\mathrm{Zn}^{2+}$ and $\mathrm{Ni}^{2+}$ on the Expression of the AdcR Regulon}

$\beta$-galactosidase activities shown above indicate that $\mathrm{Ni}^{2+}$ might compete with $\mathrm{Zn}^{2+}$ and that both metal ions have opposite effects
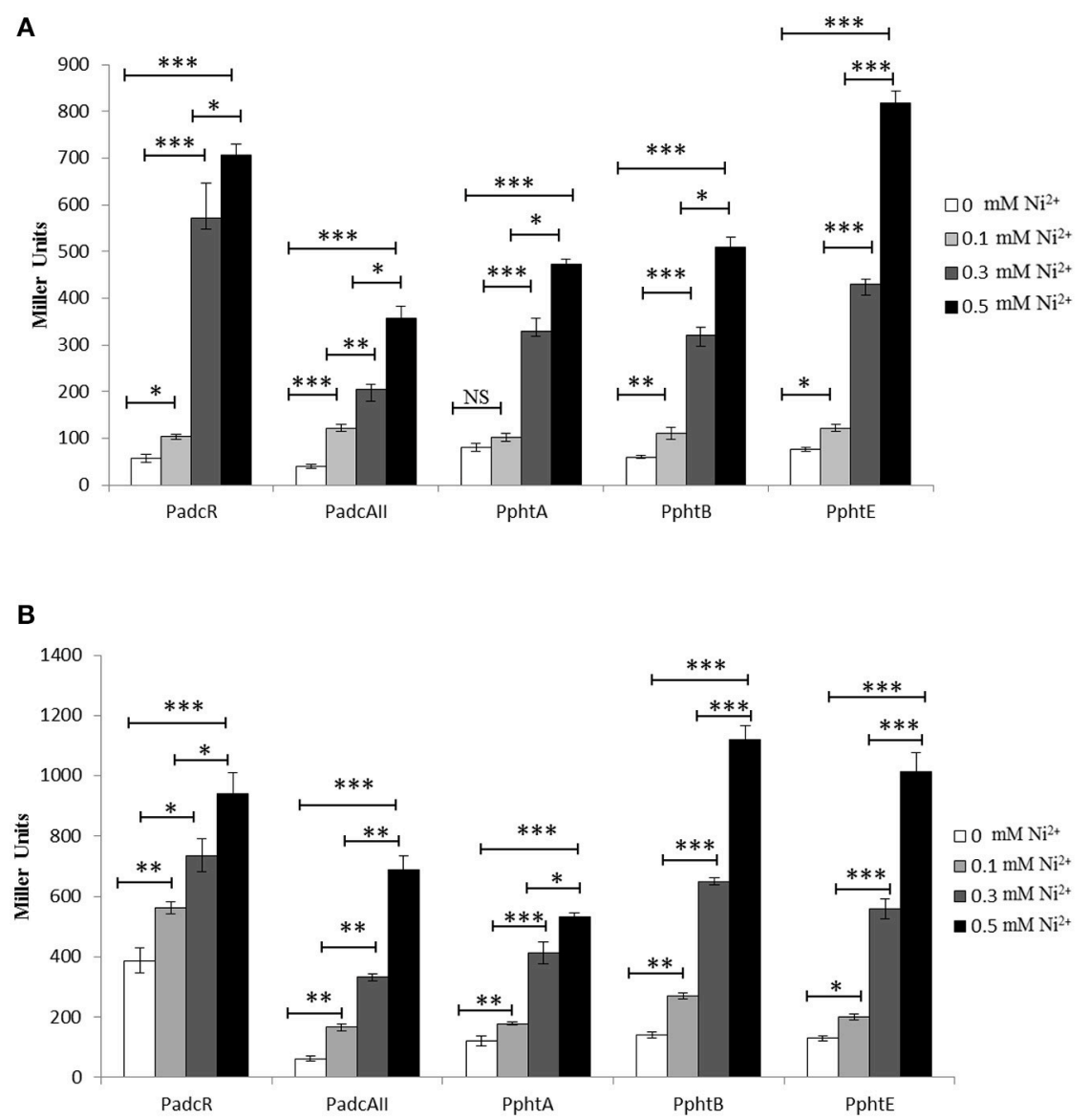

FIGURE 2 | Expression level (in Miller units) of the D39 wild-type containing transcriptional lacZ-fusions to PadcR, PadcAll, PphtA, PphtB, and PphtE, grown in CDM (A) and CDM-Zn ${ }^{2+}\left(\mathbf{Z n}^{2+}\right.$-depleted medium) (B) with different added concentrations of $\mathrm{Ni}^{2+}$. Standard deviation of three independent replications is indicated with error bars. Statistical significance of the differences in the expression levels was determined by One-way ANOVA (NS, not significant, ${ }^{\star} P<0.05,{ }^{\star \star} P<0.001$, and $\left.{ }^{* * *} P<0.0001\right)$. 
A

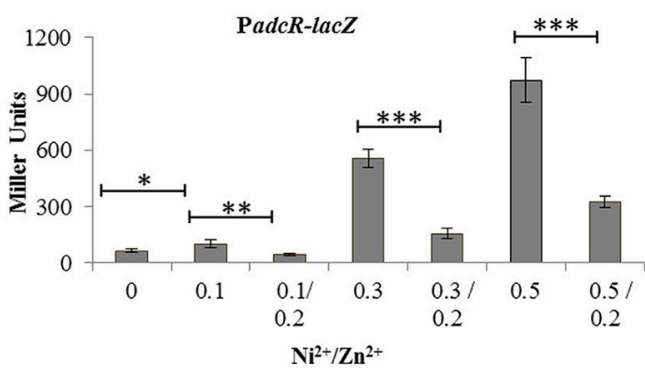

B

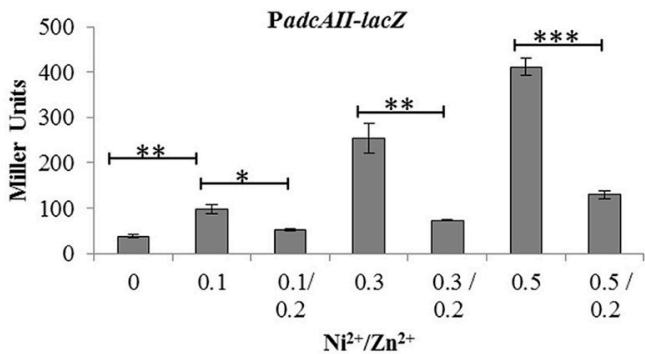

C
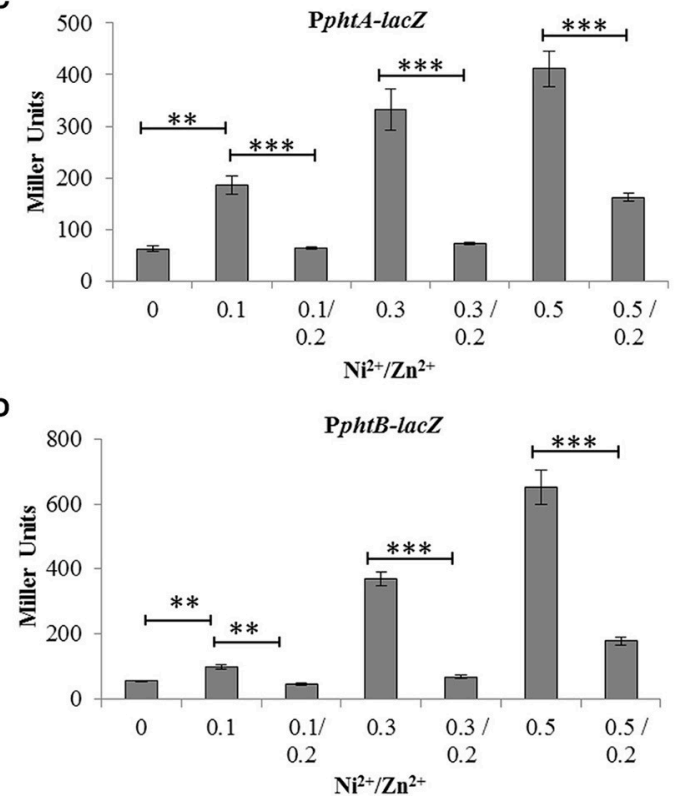

$\mathbf{E}$

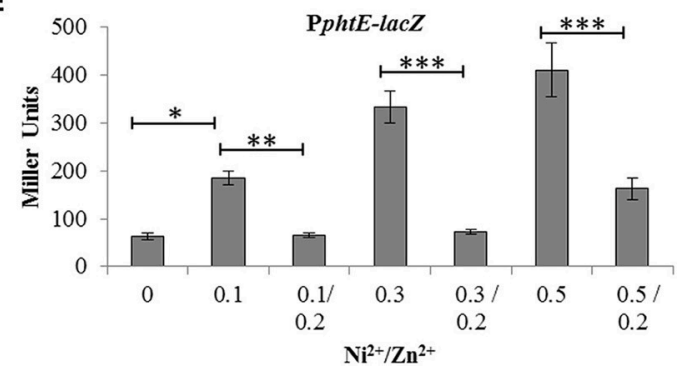

FIGURE 3 | Expression level (in Miller units) of the D39 wild-type containing transcriptional lacZ-fusions to PadcR (A), PadcAll (B), PphtA (C), PphtB (D), and PphtE (E), grown in CDM with or without addition of different concentrations of $\mathrm{Ni}^{2+}$ and $\mathrm{Zn}^{2+}$. Standard deviation of three independent replications is indicated with error bars. Statistical significance of the differences in the expression levels was determined by One-way ANOVA $\left({ }^{*} P<0.05,{ }^{* *} P<0.001\right.$, and $\left.{ }^{\star \star *} P<0.0001\right)$. on the expression of the adcRCBA, adcAII-phtD, phtA, phtB, and phtE. In order to study the interplay of $\mathrm{Ni}^{2+}$ and $\mathrm{Zn}^{2+}$ in the regulation of adcRCBA, adcAII-phtD, phtA, phtB, and pht $E$ in more details, we performed $\beta$-galactosidase assays with PadcR-lacZ, PadcAII-lacZ, PphtA-lacZ, PphtB-lacZ, and PphtElac $Z$ in $C D M$ with the addition of varying concentrations of $\mathrm{Ni}^{2+}$ and $\mathrm{Zn}^{2+}$ together. $\beta$-galactosidase data (Miller Units) showed that addition of $\mathrm{Zn}^{2+}$ in the medium leads to the repression of PadcR-lacZ, PadcAII-lacZ, PphtA-lacZ, PphtB-lacZ, and PphtElac $Z$, even in the presence of $\mathrm{Ni}^{2+}$. However, repression caused by $\mathrm{Zn}^{2+}$ was much weaker at higher concentrations of $\mathrm{Ni}^{2+}$ (Figures 3A-E). This data confirm that $\mathrm{Ni}^{2+}$ and $\mathrm{Zn}^{2+}$ have an opposite effects on the expression of adcRCBA, adcAII-phtD, pht $A$, pht $B$, and $p h t E$, where $\mathrm{Zn}^{2+}$ represses and $\mathrm{Ni}^{2+}$ derepresses the expression of these genes.

\section{Role of the Transcriptional Regulator AdcR in the $\mathrm{Ni}^{2+}$-dependent Expression of the AdcR Regulon}

Previously, it has been shown that the transcriptional regulator AdcR represses the expression of adcRCBA, adcAII-phtD, phtA, $p h t B$, and phtE in the presence of $\mathrm{Zn}^{2+}$ (Shafeeq et al., 2011a). In this study, our transcriptomic analysis and transcriptional lacZreporter data indicate that $\mathrm{Ni}^{2+}$ derepresses the expression of these genes. To identify whether the transcriptional regulator AdcR is also responsible for the $\mathrm{Ni}^{2+}$-dependent expression of adcRCBA, adcAII-phtD, phtA, phtB, and $p h t E$, we have transformed PadcR-lacZ, PadcAII-lacZ, PphtA-lacZ, PphtB-lacZ, and PphtE-lacZ into the adcR mutant (SS200) and performed $\beta$-galactosidase assays. $\beta$-galactosidase data revealed that the deletion of $a d c R$ leads to increase expression of PadcR-lacZ, PadcAII-lacZ, PphtA-lacZ, PphtB-lacZ, and PphtE-lacZ even in the absence of $\mathrm{Ni}^{2+}$ (Figure 4). Upregulation of these transcriptional lacZ-fusions in the $a d c R$ mutant indicates that $\mathrm{Ni}^{2+}$-dependent expression of adcRCBA, adcAII-phtD, phtA, $p h t B$, and $p h t E$ is mediated by transcriptional regulator AdcR.

To elucidate the $\mathrm{Ni}^{2+}$-dependent role of $\mathrm{AdcR}$ in more details and find more targets of AdcR in the presence of $\mathrm{Ni}^{2+}$, microarray comparison of the $a d c R$ mutant with D39 wildtype was performed in CDM with $0.3 \mathrm{mM} \mathrm{Ni}^{2+}$. As expected, the expression of genes belonging to the AdcR regulon was highly upregulated (Table 4), except for the adc operon, which was downregulated in our transcriptome analysis (Table 4). For creating an $a d c R$ mutant in previous study, an erythromycinresistance gene cassette was used to replace the $a d c R$ gene (Shafeeq et al., 2011a). Therefore, downregulation of the adc operon might be due to the polar effect of $a d c R$ deletion on the downstream genes of $a d c R$ (Shafeeq et al., 2011a). We further validated our DNA microarray data by qRT-PCR. qRT-PCR data is also in agreement with our transcriptome data (Supplementary data: Table S2).

\section{Binding of AdcR to Its Target Is $\mathrm{Zn}^{2+}$-and $\mathrm{Ni}^{2+}$-dependent}

To study the direct interaction of $\mathrm{AdcR}$ with the promoter regions of the genes belonging to the AdcR regulon in the 


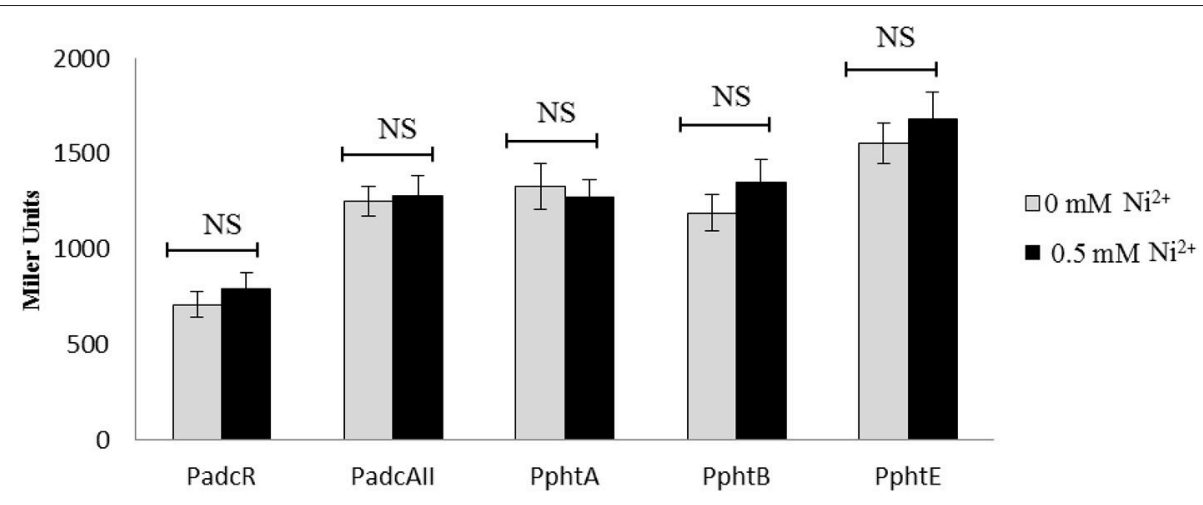

FIGURE 4 | Expression level (in Miller units) of the adcR mutant containing transcriptional lacZ-fusions to PadcR, PadcAll, PphtA, PphtB, and PphtE grown in CDM with or without addition of $\mathbf{0 . 5} \mathbf{~ m M ~ N i}{ }^{2+}$. Standard deviation of three independent replications is indicated with error bars. Statistical significance of the differences in the expression levels was determined by One-way ANOVA (NS, not significant).

TABLE 4 | Summary of transcriptome comparison of S. pneumoniae D39 wild-type with $\triangle a d c R$ (SS200) grown in CDM with $0.3 \mathrm{mM} \mathrm{Ni}^{2+}$.

\begin{tabular}{|c|c|c|c|}
\hline Gene tag ${ }^{a}$ & Function $^{\mathbf{b}}$ & Ratioc & $P$-value \\
\hline SPD0126 & Pneumococcal surface protein A, PhpA & 2.29 & 1.35E-05 \\
\hline SPD0277 & 6- phospho-beta-glucosidase, CelA & 12.36 & $2.28 \mathrm{E}-13$ \\
\hline SPD0278 & Hypothetical protein & 6.67 & $1.12 \mathrm{E}-09$ \\
\hline SPD0279 & PTS system, IIB component, CelB & 7.82 & 3.99E-09 \\
\hline SPD0280 & Transcriptional regulator, CelR & 10.24 & $2.71 E-12$ \\
\hline SPD0281 & PTS system, IIA component, CelC & 4.80 & 1.75E-07 \\
\hline SPD0282 & Hypothetical protein & 6.8 & $6.87 \mathrm{E}-10$ \\
\hline SPD0283 & PTS system, IIC component, CelD & 7.10 & 8.67E-09 \\
\hline SPD0308 & $\begin{array}{l}\text { ATP-dependent Clp protease, } \\
\text { ATP-binding subunit, ClpL }\end{array}$ & 4.21 & $5.54 \mathrm{E}-10$ \\
\hline SPD0888 & Adhesion lipoprotein, AdcAll (LmB) & 1.65 & 3.39E-04 \\
\hline SPD0889 & $\begin{array}{l}\text { Pneumococcal histidine triad protein D, } \\
\text { PhtD }\end{array}$ & 3.51 & $1.21 \mathrm{E}-08$ \\
\hline SPD0893 & Hypothetical protein & 3.51 & $8.62 \mathrm{E}-07$ \\
\hline SPD1038 & $\begin{array}{l}\text { Pneumococcal histidine triad protein A, } \\
\text { PhtA }\end{array}$ & 5.59 & 8.67E-09 \\
\hline SPD1514 & ABC transporter, ATP-binding protein & -3.35 & $4.04 \mathrm{E}-08$ \\
\hline SPD1515 & Hypothetical protein & -4.06 & $4.50 E-09$ \\
\hline SPD1516 & Hypothetical protein & -4.57 & $3.25 E-09$ \\
\hline SPD1997 & $\begin{array}{l}\text { Zinc ABC transporter, zinc-binding } \\
\text { lipoprotein, AdcA }\end{array}$ & -18.45 & $4.07 \mathrm{E}-13$ \\
\hline SPD1998 & $\begin{array}{l}\text { Zinc ABC transporter, permease protein, } \\
\text { AdcB }\end{array}$ & -2.71 & $1.29 \mathrm{E}-04$ \\
\hline SPD1999 & $\begin{array}{l}\text { Zinc ABC transporter, ATP-binding protein, } \\
\text { AdcC }\end{array}$ & -10.76 & $3.21 \mathrm{E}-12$ \\
\hline SPD2000 & adc operon repressor, AdcR & -15.29 & $7.99 \mathrm{E}-11$ \\
\hline SPD2001 & Hypothetical protein & -25.05 & $1.31 \mathrm{E}-12$ \\
\hline
\end{tabular}

a Gene numbers refer to D39 locus tags.

${ }^{b}$ D39 annotation/TIGR4 annotation (Hoskins et al., 2001; Lanie et al., 2007).

${ }^{c}$ Ratios $>2.0$ or $<2.0$ (SS200 +0.3 $\mathrm{mM} \mathrm{Ni}^{2+}$ / wild-type $+0.3 \mathrm{mM} \mathrm{Ni}^{2+}$ ).

presence of $\mathrm{Ni}^{2+}$, we performed EMSAs with purified Streptagged AdcR (Ad-Strep tag) and ${ }^{33}$ P-labeled promoters of $a d c R$, $a d c A I I, p h t A, p h t B$, and $p c p A$. To prevent the interference of metal ions with Ad-Strep tag, all the experiments were performed in EDTA free gels and buffers. The $p c p A$ promoter region was taken as a negative control. Ad-Strep tag was unable to shift the promoter regions of $a d c R, a d c A I I, p h t A$, and $p h t B$ in the absence of metal ions (Lane 2 in Figure 5). However,

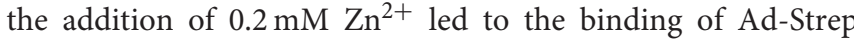
tag to the promoter regions of $a d c R$, adcAII, pht A, and phtB (Lane 3 in Figures 5A-D), which is consistent with our previous study (Shafeeq et al., 2011a). Interestingly, 0.2 and $0.4 \mathrm{mM} \mathrm{Ni}^{2+}$ were unable to stimulate the binding of Ad-Strep tag with the promoter regions of $a d c R, a d c A I I$, pht $A$, and phtB (Lane 4 and 5 in Figures 5A-D). In our transcriptome data mentioned above, $\mathrm{Ni}^{2+}$ showed a derepressive effect on the expression of the AdcR regulon. Therefore, we also decided to check the interaction of Ad-Strep tag with the promoter regions of adcR, adcAII, phtA, and $p h t B$ in the presence of both $\mathrm{Zn}^{2+}$ and $\mathrm{Ni}^{2+}$ together. The $\mathrm{Zn}^{2+}$-dependent interaction of AdcR with these promoters in the presence of $0.2 \mathrm{mM} \mathrm{Zn^{2+ }}$ was alleviated with the addition of $0.2 \mathrm{mM}$ or $0.4 \mathrm{mM} \mathrm{Ni}^{2+}$ (Lane 6 and 7 in Figures 5A-D). Under the same conditions, we did not see any band shift with the promoter region of $p c p A$ as a negative control (Figure 5E). Thus, this data indicates that $\mathrm{Zn}^{2+}$ and $\mathrm{Ni}^{2+}$ have an opposite effects on the interaction of $A d c R$ with the promoter regions of adcR, adcAII, phtA, and phtB.

\section{Effect of $\mathrm{Ni}^{2+}$ on SczA-mediated Expression of the $\mathrm{Zn}^{2+}$-efflux system $\mathrm{czcD}$}

To investigate the regulation of $c z c D$ in the presence of $\mathrm{Ni}^{2+}$, we studied the transcriptional response of $\mathrm{P} c z c D-l a c Z$ grown in complete CDM with the addition of different concentrations of $\mathrm{Ni}^{2+} . \beta$-galactosidase assays showed that $\mathrm{P} c z c D$-lac $Z$ responded to $\mathrm{Ni}^{2+}$ and its expression was highly increased with an increasing concentration of $\mathrm{Ni}^{2+}$ (Figure 6). This data is in agreement with our transcriptomic data mentioned above and suggests the putative role of $\mathrm{CzcD}$ in $\mathrm{Ni}^{2+}$ homeostasis.

\section{DISCUSSION}

Transition metal ions such as $\mathrm{Mn}^{2+}, \mathrm{Zn}^{2+}, \mathrm{Cu}^{2+}, \mathrm{Fe}^{2+}, \mathrm{Co}^{2+}$, and $\mathrm{Cd}^{2+}$ have been shown to play a pivotal role in the 


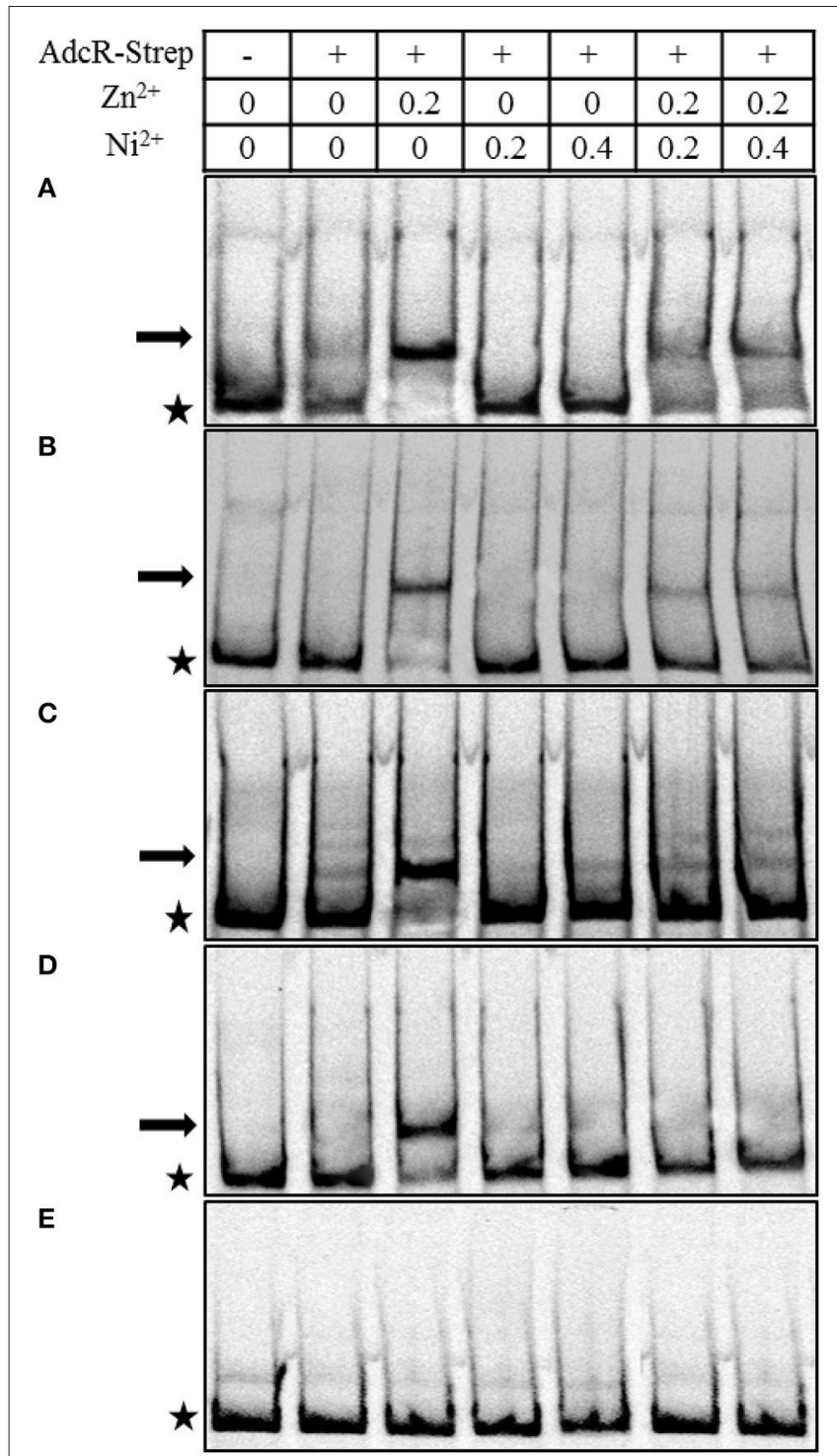

FIGURE 5 | In vitro interaction of Ad-Strep tag with the promoter regions of adcR (A), adcAll (B), phtA (C), phtB (D), and pcpA (E). Ad-Strep was added at a concentration of $30 \mathrm{nM}$ as indicated above panel, while lane 1 is without added protein. Arrows indicate the position of shifted probe and asterisks indicate the position of free probe. $0.2 \mathrm{mM} \mathrm{Zn}^{2+}$ was added in lanes 3,6 , and 7 . Whereas, $\mathrm{Ni}^{2+}$ was added at the concentration of $0.2 \mathrm{mM}$ in lane 4 and 6 , and $0.4 \mathrm{mM}$ in lanes 5 and 7 .

metabolism and virulence of S. pneumoniae (Brown et al., 2001; Kloosterman et al., 2008; Shafeeq et al., 2011b; Begg et al., 2015). However, the role of $\mathrm{Ni}^{2+}$ on the global gene expression of S. pneumoniae has not been studied before. In this study, we analyze the transcriptome changes in S. pneumoniae D39 wildtype in response to high $\mathrm{Ni}^{2+}$ concentration. The expression of a number of important genes and operons with diverse functions, including the AdcR regulon ( $a d c R C B A, a d c A I I-p h t D$, phtA, phtB, and $p h t E$ ), the PsaR regulon ( $p c p A$, prtA, and $p s a B C A$ ) regulon, and the $\mathrm{Zn}^{2+}$-efflux system $c z c D$ were significantly altered in the

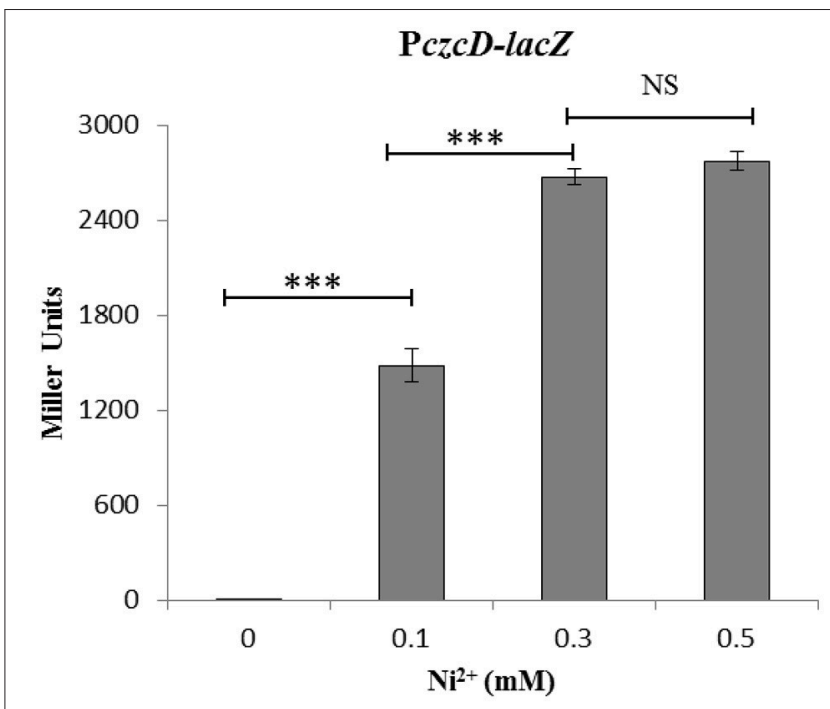

FIGURE 6 | Expression level (miller units) of the D39 wild-type containing transcriptional lacZ-fusion to PczcD grown in CDM with different added concentrations of $\mathrm{Ni}^{2+}$. Standard deviation of three independent replications is indicated with error bars. Statistical significance of the differences in the expression levels was determined by One-way ANOVA (NS, not significant and ${ }^{* *} P<0.0001$ ).

presence of $\mathrm{Ni}^{2+}$. We further studied the role of $\mathrm{Ni}^{2+}$ in the regulation of the $\mathrm{AdcR}$ regulon and demonstrated that $\mathrm{Ni}^{2+}$ plays an opposite role compared to $\mathrm{Zn}^{2+}$ in the regulation of the $\mathrm{AdcR}$ regulon.

The AdcR regulon consists of $\operatorname{adcRCBA}$, adcAII-phtD, phtA, $p h t B$, phtE, and $a d h C$ in $S$. pneumoniae. The adc operon (adcRCBA) is involved in $\mathrm{Zn}^{2+}$ acquisition, and encodes for a $\mathrm{Zn}^{2+}$-responsive MarR family transcriptional regulator, $\mathrm{AdcR}$, two $\mathrm{ABC}$ transporter proteins $\mathrm{AdcC}$ and $\mathrm{AdcB}$, and an extracellular $\mathrm{Zn}^{2+}$-binding protein AdcA (Dintilhac et al., 1997; Dintilhac and Claverys, 1997; Bayle et al., 2011). The adcAII gene encodes an adhesion lipoprotein which has an overlapping specificity with AdcA for $\mathrm{Zn}^{2+}$ (Bayle et al., 2011). AdcAII belongs to the LraI-lipoprotein family and is organized in an operon with a phtD gene encoding pneumococcal histidine triade protein precursor $\mathrm{D}$ ( $\mathrm{PhtD}$ ). phtA, phtB, and phtE encodes for pneumococcal histidine triade protein $\mathrm{A}, \mathrm{B}$, and $\mathrm{E}$, respectively. Recent studies have demonstrated the role of the PhT family proteins (PhtA, PhtB, PhtE, and PhtD) in intracellular $\mathrm{Zn}^{2+}$ acquisition and pathogenesis in S. pneumoniae (Hava and Camilli, 2002; Ogunniyi et al., 2009; Plumptre et al., 2014b). The adhC gene encodes for a $\mathrm{Zn}^{2+}$-containing alcohol dehydrogenase. Previously, it was demonstrated that the expression of $a d c R C B A, a d c A I I-p h t D$, pht $A$, phtB, and phtE is repressed, while the expression of $a d h C$ is activated by the transcriptional regulator AdcR in the presence of $\mathrm{Zn}^{2+}$ (Shafeeq et al., 2011a). Here, we show that $\mathrm{Ni}^{2+}$ also plays a role in the regulation of adcRCBA, adcAII-phtD, phtA, phtB, and phtE. Our $\beta$-galactosidase assays showed that the expression of $a d c R C B A$, adcAII-phtD, pht $A$, phtB, and $p h t E$ was increased with increasing concentrations of $\mathrm{Ni}^{2+}$. However, we did not find any significant 
change in the expression of $a d h C$ in our both transcriptome analysis performed in this study. This might exclude the role of $\mathrm{Ni}^{2+}$ in the AdcR mediated regulation of adhC.

High concentrations of $\mathrm{Ni}^{2+}$ can be very toxic for bacteria (Macomber and Hausinger, 2011). Therefore, bacteria must limit the toxic amount of $\mathrm{Ni}^{2+}$ to perform normal cellular functions. In many bacteria, CDF-family efflux pumps help to maintain proper concentrations of heavy metals in the cell. For example, in Bacillus subtilis, the CzcD heavy metal efflux pump is involved in the homeostasis of $\mathrm{Zn}^{2+}, \mathrm{Co}^{2+}, \mathrm{Cu}^{2+}$, and $\mathrm{Ni}^{2+}$, and is regulated by CzrA (Moore et al., 2005). It is also important to note that the expression of $c z c D$ is highly upregulated in our transcriptome analysis in response to $\mathrm{Ni}^{2+}$. Expression of $c z c D$ is regulated by the TetR family transcriptional regulator SczA in the presence of $\mathrm{Zn}^{2+}, \mathrm{Co}^{2+}$, or $\mathrm{Ni}^{2+}$ (Kloosterman et al., 2007). Moreover, $\mathrm{Zn}^{2+}, \mathrm{Co}^{2+}$, or $\mathrm{Ni}^{2+}$ has been shown to stimulate the binding of SczA to the promoter region of $c z c D$ (Kloosterman et al., 2007). In this study, we further confirmed the expression of $c z c D$ in the presence of $\mathrm{Ni}^{2+}$ by transcriptional lacZ-reporter study with PczcD-lacZ and our results are consistent with a previous study (Kloosterman et al., 2007).

The PsaR regulon consists of $p s a B C A, p c p A$, and $p r t A$ that encodes for the $\mathrm{Mn}^{2+}$ uptake system (PsaBCA), a choline binding protein $(\mathrm{PcpA})$, and a serine protease (PrtA), respectively. The expression of the PsaR regulon is shown to be repressed by the DtxR family transcriptional regulator PsaR in the presence of $\mathrm{Mn}^{2+}$ (Johnston et al., 2006). Notably, $\mathrm{Zn}^{2+}$ and $\mathrm{Co}^{2+}$ can bind with PsaR to relieve the $\mathrm{Mn}^{2+}$-dependent repression of the PsaR regulon (Kloosterman et al., 2008; Manzoor et al., 2015a). Recently, we have studied the regulation of the PsaR regulon in the presence of $\mathrm{Ni}^{2+}$ and demonstrated that like $\mathrm{Zn}^{2+}$ and $\mathrm{Co}^{2+}, \mathrm{Ni}^{2+}$ also has the ability to derepress the $\mathrm{Mn}^{2+}$-dependent repression of the PsaR regulon, and that high concentrations of $\mathrm{Ni}^{2+}$ leads to cell-associated $\mathrm{Mn}^{2+}$ deficiency (Manzoor et al., 2015b). In this study, we have also observed the significant upregulation of the PsaR regulon in our transcriptome analysis performed in the presence of $\mathrm{Ni}^{2+}$ (Table 3). Upregulation of the PsaR regulon in our transcriptome further verifies our previous

\section{REFERENCES}

Afzal, M., Manzoor, I., and Kuipers, O. P. (2015). A fast and reliable pipeline for bacterial transcriptome analysis case study: serine-dependent gene regulation in Streptococcus pneumoniae. J. Vis. Exp. e52649. doi: 10.3791/52649

Alimonti, A., Bocca, B., Mannella, E., Petrucci, F., Zennaro, F., Cotichini, R., et al. (2005). Assessment of reference values for selected elements in a healthy urban population. Ann. Ist. Super. Sanità 41, 181-187.

Anwar, H. A., Aldam, C. H., Visuvanathan, S., and Hart, A. J. (2007). The effect of metal ions in solution on bacterial growth compared with wear particles from hip replacements. J. Bone Joint Surg. Br. 89-B, 1655-1659. doi: 10.1302/0301620X.89B12.19714

Bayle, L., Chimalapati, S., Schoehn, G., Brown, J., Vernet, T., and Durmort, C. (2011). Zinc uptake by Streptococcus pneumoniae depends on both AdcA and AdcAII and is essential for normal bacterial morphology and virulence. Mol. Microbiol. 82, 904-916. doi: 10.1111/j.1365-2958.2011. 07862.x

Begg, S. L., Eijkelkamp, B. A., Luo, Z., Couñago, R. M., Morey, J. R., Maher, M. J., et al. (2015). Dysregulation of transition metal ion homeostasis is the molecular results (Manzoor et al., 2015b). Moreover, we have also observed the cell-associated deficiency of $\mathrm{Mn}^{2+}$ in our ICP-MS analysis performed in this study (Figure 1), which is also in consistent with our previous results (Manzoor et al., 2015b).

The interplay, or competition, of metal ions plays an important role in the regulation of metal responsive genes. In $S$. pneumoniae, competition of $\mathrm{Mn}^{2+}$ with $\mathrm{Zn}^{2+}, \mathrm{Co}^{2+}$, or $\mathrm{Ni}^{2+}$ in the regulation of the PsaR regulon by transcriptional regulator PsaR has already extensively been studied (Kloosterman et al., 2008; Manzoor et al., 2015a,b). Similarly, the interplay of $\mathrm{Cu}^{2+}$ and $\mathrm{Zn}^{2+}$ in the regulation of cop operon by transcriptional regulator CopY was studied before, where $\mathrm{Cu}^{2+}$ induces and $\mathrm{Zn}^{2+}$ represses the CopY-mediated expression of cop operon (Shafeeq et al., 2011b). Here, we elaborated for the first time the interplay of $\mathrm{Ni}^{2+}$ and $\mathrm{Zn}^{2+}$ in the regulation of genes belonging to the AdcR regulon. Our lacZ-reporter studies determined the ability of $\mathrm{Ni}^{2+}$, in derepressing the $\mathrm{Zn}^{2+}$-dependent repression of adcRCBA, adcAII-phtD, phtA, phtB, and phtE. Our in vitro data showed that the $\mathrm{Zn}^{2+}$-dependent binding of AdcR to the promoter regions of the genes belonging to the $\mathrm{AdcR}$ regulon was alleviated by the addition of $\mathrm{Ni}^{2+}$. Recently, it has been shown that $\mathrm{Cd}^{2+}$-uptake reduces the accumulation of cell-associated $\mathrm{Mn}^{2+}$ and $\mathrm{Zn}^{2+}$ (Begg et al., 2015). Our ICP-MS comparison of cells grown in CDM with $0.5 \mathrm{mM}$ to $0 \mathrm{mM} \mathrm{Ni}^{2+}$ has not shown any difference in the concentration of $\mathrm{Zn}^{2+}$ or other metal ions, which also indicates the direct role of $\mathrm{Ni}^{2+}$ in the regulation of adcRCBA, adcAII-phtD, phtA, phtB, and phtE. Moreover, the role of genes belonging to the AdcR regulon in the pathogenesis of $S$. pneumoniae has already been demonstrated, which also suggests the important role of $\mathrm{Ni}^{2+}$ in pneumococcal virulence.

\section{SUPPLEMENTARY MATERIAL}

The Supplementary Material for this article can be found online at: http://journal.frontiersin.org/article/10.3389/fcimb. 2015.00091 basis for cadmium toxicity in Streptococcus pneumoniae. Nat. Commun. 6:6418 doi: $10.1038 /$ ncomms7418

Blencowe, D. K., and Morby, A. P. (2003). Zn(II) metabolism in prokaryotes. FEMS Microbiol. Rev. 27, 291-311. doi: 10.1016/S0168-6445(03)00041-X

Bogaert, D., De Groot, R., and Hermans, P. W. M. (2004). Streptococcus pneumoniae colonisation: the key to pneumococcal disease. Lancet Infect. Dis. 4, 144-154. doi: 10.1016/S1473-3099(04)00938-7

Brown, J. S., Gilliland, S. M., and Holden, D. W. (2001). A Streptococcus pneumoniae pathogenicity island encoding an $\mathrm{ABC}$ transporter involved in iron uptake and virulence. Mol. Microbiol. 40, 572-585. doi: 10.1046/j.13652958.2001.02414.x

Cavet, J. S., Meng, W., Pennella, M. A., Appelhoff, R. J., Giedroc, D. P., and Robinson, N. J. (2002). A nickel-cobalt-sensing ArsR-SmtB family repressor. Contributions of cytosol and effector binding sites to metal selectivity. J. Biol. Chem. 277, 38441-38448. doi: 10.1074/jbc. M207677200

Chen, Y.-Y. M., and Burne, R. A. (2003). Identification and characterization of the nickel uptake system for urease biogenesis in Streptococcus salivarius 57.I. J. Bacteriol. 185, 6773-6779. doi: 10.1128/JB.185.23.6773-6779.2003 
De Pina, K., Desjardin, V., Mandrand-Berthelot, M. A., Giordano, G., and Wu, L. F. (1999). Isolation and characterization of the nikR gene encoding a nickel-responsive regulator in Escherichia coli. J. Bacteriol. 181, 670-674.

Dintilhac, A., Alloing, G., Granadel, C., and Claverys, J. P. (1997). Competence and virulence of Streptococcus pneumoniae: Adc and PsaA mutants exhibit a requirement for $\mathrm{Zn}$ and $\mathrm{Mn}$ resulting from inactivation of putative ABC metal permeases. Mol. Microbiol. 25, 727-739. doi: 10.1046/j.13652958.1997.5111879.x

Dintilhac, A., and Claverys, J. P. (1997). The adc locus, which affects competence for genetic transformation in Streptococcus pneumoniae, encodes an ABC transporter with a putative lipoprotein homologous to a family of streptococcal adhesins. Res. Microbiol. 148, 119-131. doi: 10.1016/S0923-2508(97)87643-7

Finney, L. A., and O'Halloran, T. V. (2003). Transition metal speciation in the cell: insights from the chemistry of metal ion receptors. Science 300, 931-936. doi: 10.1126/science.1085049

Ge, R., Chen, Z., and Zhou, Q. (2012). The actions of bismuth in the treatment of Helicobacter pylori infections: an update. Met. Integr. Biometal Sci. 4, 239-243. doi: $10.1039 / \mathrm{c} 2 \mathrm{mt} 00180 \mathrm{~b}$

Gupta, R., Shah, P., and Swiatlo, E. (2009). Differential gene expression in Streptococcus pneumoniae in response to various iron sources. Microb. Pathog. 47, 101-109. doi: 10.1016/j.micpath.2009.05.003

Halfmann, A., Hakenbeck, R., and Brückner, R. (2007). A new integrative reporter plasmid for Streptococcus pneumoniae. FEMS Microbiol. Lett. 268, 217-224. doi: 10.1111/j.1574-6968.2006.00584.x

Hava, D. L., and Camilli, A. (2002). Large-scale identification of serotype 4 Streptococcus pneumoniae virulence factors. Mol. Microbiol. 45, 1389-1406. doi: 10.1046/j.1365-2958.2002.03106.x

Hendriksen, W. T., Bootsma, H. J., van Diepen, A., Estevão, S., Kuipers, O. P., de Groot, R., et al. (2009). Strain-specific impact of PsaR of Streptococcus pneumoniae on global gene expression and virulence. Microbiol. Read. Engl. 155, 1569-1579. doi: 10.1099/mic.0.025072-0

Hoskins, J., Alborn, W. E. Jr., Arnold, J., Blaszczak, L. C., Burgett, S., DeHoff, B. S., et al. (2001). Genome of the bacterium Streptococcus pneumoniae strain R6. J. Bacteriol. 183, 5709-5717. doi: 10.1128/JB.183.19.5709-5717.2001

Jacobsen, F. E., Kazmierczak, K. M., Lisher, J. P., Winkler, M. E., and Giedroc, D. P. (2011). Interplay between manganese and zinc homeostasis in the human pathogen Streptococcus pneumoniae. Met. Integr. Biometal Sci. 3, 38-41. doi: 10.1039/C0MT00050G

Johnston, J. W., Briles, D. E., Myers, L. E., and Hollingshead, S. K. (2006). Mn²+dependent regulation of multiple genes in Streptococcus pneumoniae through PsaR and the resultant impact on virulence. Infect. Immun. 74, 1171-1180. doi: 10.1128/IAI.74.2.1171-1180.2006

Kloosterman, T. G., Hendriksen, W. T., Bijlsma, J. J. E., Bootsma, H. J., van Hijum, S. A. F. T., Kok, J., et al. (2006). Regulation of glutamine and glutamate metabolism by GlnR and GlnA in Streptococcus pneumoniae. J. Biol. Chem. 281, 25097-25109. doi: 10.1074/jbc.M601661200

Kloosterman, T. G., van der Kooi-Pol, M. M., Bijlsma, J. J. E., and Kuipers, O. P. (2007). The novel transcriptional regulator SczA mediates protection against $\mathrm{Zn}^{2+}$ stress by activation of the $\mathrm{Zn}^{2+}$-resistance gene $\mathrm{cZcD}$ in Streptococcus pneumoniae. Mol. Microbiol. 65, 1049-1063. doi: 10.1111/j.13652958.2007.05849.x

Kloosterman, T. G., Witwicki, R. M., van der Kooi-Pol, M. M., Bijlsma, J. J. E., and Kuipers, O. P. (2008). Opposite effects of $\mathrm{Mn}^{2+}$ and $\mathrm{Zn}^{2+}$ on PsaR-mediated expression of the virulence genes pcpA, prtA, and psaBCA of Streptococcus pneumoniae. J. Bacteriol. 190, 5382-5393. doi: 10.1128/JB. 00307-08

Kuipers, O. P., de Ruyter, P. G. G., Kleerebezem, M., and de Vos, W. M. (1998). Quorum sensing-controlled gene expression in lactic acid bacteria. J. Biotechnol. 64, 15-21. doi: 10.1016/S0168-1656(98)00100-X

Lanie, J. A., Ng, W.-L., Kazmierczak, K. M., Andrzejewski, T. M., Davidsen, T. M., Wayne, K. J., et al. (2007). Genome sequence of Avery's virulent serotype 2 strain D39 of Streptococcus pneumoniae and comparison with that of unencapsulated laboratory strain R6. J. Bacteriol. 189, 38-51. doi: 10.1128/JB.01148-06

Lisher, J. P., Higgins, K. A., Maroney, M. J., and Giedroc, D. P. (2013). Physical Characterization of the manganese-sensing pneumococcal surface antigen repressor from Streptococcus pneumoniae. Biochemistry (Mosc.) 52, 7689-7701. doi: $10.1021 /$ bi401132w
Macomber, L., and Hausinger, R. P. (2011). Mechanisms of nickel toxicity in microorganisms. Met. Integr. Biometal Sci. 3, 1153-1162. doi: $10.1039 / \mathrm{clmt} 00063 \mathrm{~b}$

Manzoor, I., Shafeeq, S., Kloosterman, T. G., and Kuipers, O. P. (2015a). Co ${ }^{2+}$ dependent gene expression in Streptococcus pneumoniae: opposite effect of $\mathrm{Mn}^{2+}$ and $\mathrm{Co}^{2+}$ on the expression of the virulence genes psaBCA, pcpA and prtA. Microb. Physiol. Metab. 6, 748. doi: 10.3389/fmicb.2015.00748

Manzoor, I., Shafeeq, S., and Kuipers, O. P. (2015b). $\mathrm{Ni}^{2+}$-dependent and PsaR-mediated regulation of the virulence genes pcpA, psaBCA and prtA in Streptococcus pneumoniae. PLoS ONE 10:e142839. doi: 10.1371/journal.pone.0142839

Manzoor, I., Shafeeq, S., and Kuipers, O. P. (2015c). Transcriptome analysis of Streptococcus pneumoniae D39 in the presence of cobalt. Genomics Data 6, 151-153. doi: 10.1016/j.gdata.2015.08.033

Mitchell, T. J. (2003). The pathogenesis of streptococcal infections: from tooth decay to meningitis. Nat. Rev. Microbiol. 1, 219-230. doi: 10.1038/nrmicro771

Moore, C. M., Gaballa, A., Hui, M., Ye, R. W., and Helmann, J. D. (2005). Genetic and physiological responses of Bacillus subtilis to metal ion stress. Mol. Microbiol. 57, 27-40. doi: 10.1111/j.1365-2958.2005.04642.x

Moore, C. M., and Helmann, J. D. (2005). Metal ion homeostasis in Bacillus subtilis. Curr. Opin. Microbiol. 8, 188-195. doi: 10.1016/j.mib.2005.02.007

Mulrooney, S. B., and Hausinger, R. P. (2003). Nickel uptake and utilization by microorganisms. FEMS Microbiol. Rev. 27, 239-261. doi: 10.1016/S01686445(03)00042-1

Obaro, S., and Adegbola, R. (2002). The pneumococcus: carriage, disease and conjugate vaccines. J. Med. Microbiol. 51, 98-104. doi: 10.1099/0022-1317-512-98

Ogunniyi, A. D., Grabowicz, M., Mahdi, L. K., Cook, J., Gordon, D. L., Sadlon, T. A., et al. (2009). Pneumococcal histidine triad proteins are regulated by the $\mathrm{Zn}^{2+}$-dependent repressor AdcR and inhibit complement deposition through the recruitment of complement factor H. FASEB J. 23, 731-738. doi: 10.1096/fj.08-119537

Plumptre, C. D., Eijkelkamp, B. A., Morey, J. R., Behr, F., Couñago, R. M., Ogunniyi, A. D., et al. (2014a). AdcA and AdcAII employ distinct zinc acquisition mechanisms and contribute additively to zinc homeostasis in Streptococcus pneumoniae. Mol. Microbiol. 91, 834-851. doi: 10.1111/mmi.12504

Plumptre, C. D., Hughes, C. E., Harvey, R. M., Eijkelkamp, B. A., McDevitt, C. A., and Paton, J. C. (2014b). Overlapping Functionality of the Pht Proteins in Zinc Homeostasis of Streptococcus pneumoniae. Infect. Immun. 82, 4315-4324. doi: 10.1128/IAI.02155-14

Pulliainen, A. T., Haataja, S., Kähkönen, S., and Finne, J. (2003). Molecular basis of $\mathrm{H} 2 \mathrm{O} 2$ resistance mediated by Streptococcal Dpr. Demonstration of the functional involvement of the putative ferroxidase center by sitedirected mutagenesis in Streptococcus suis. J. Biol. Chem. 278, 7996-8005. doi: 10.1074/jbc.M210174200

Rodionov, D. A., Hebbeln, P., Gelfand, M. S., and Eitinger, T. (2006). Comparative and functional genomic analysis of prokaryotic nickel and cobalt uptake transporters: evidence for a novel group of ATP-binding cassette transporters. J. Bacteriol. 188, 317-327. doi: 10.1128/JB.188.1.317-327.2006

Rosch, J. W., Gao, G., Ridout, G., Wang, Y.-D., and Tuomanen, E. I. (2009). Role of the manganese efflux system mntE for signalling and pathogenesis in Streptococcus pneumoniae. Mol. Microbiol. 72, 12-25. doi: 10.1111/j.13652958.2009.06638.x

Shafeeq, S., Kloosterman, T. G., and Kuipers, O. P. (2011a). Transcriptional response of Streptococcus pneumoniae to $\mathrm{Zn}^{2+}$ ) limitation and the repressor/activator function of AdcR. Met. Integr. Biometal Sci. 3, 609-618. doi: $10.1039 / \mathrm{clmt} 00030 \mathrm{f}$

Shafeeq, S., Kuipers, O. P., and Kloosterman, T. G. (2013). The role of zinc in the interplay between pathogenic streptococci and their hosts. Mol. Microbiol. 88, 1047-1057. doi: $10.1111 / \mathrm{mmi} .12256$

Shafeeq, S., Yesilkaya, H., Kloosterman, T. G., Narayanan, G., Wandel, M., Andrew, P. W., et al. (2011b). The cop operon is required for copper homeostasis and contributes to virulence in Streptococcus pneumoniae. Mol. Microbiol. 81, 1255-1270. doi: 10.1111/j.1365-2958.2011.07758.x

Sun, X., Yu, G., Xu, Q., Li, N., Xiao, C., Yin, X., et al. (2013). Putative cobalt- and nickel-binding proteins and motifs in Streptococcus pneumoniae. Met. Integr. Biometal Sci. 5, 928-935. doi: 10.1039/c3mt00126a 
Tottey, S., Waldron, K. J., Firbank, S. J., Reale, B., Bessant, C., Sato, K., et al. (2008). Protein-folding location can regulate manganese-binding versus copper- or zinc-binding. Nature 455, 1138-1142. doi: 10.1038/nature07340

van Vliet, A. H. M., Kuipers, E. J., Waidner, B., Davies, B. J., de Vries, N., Penn, C. W., et al. (2001). Nickel-responsive induction of urease expression inhelicobacter pylori is mediated at the transcriptional level. Infect. Immun. 69, 4891-4897. doi: 10.1128/IAI.69.8.4891-4897.2001

Waldron, K. J., and Robinson, N. J. (2009). How do bacterial cells ensure that metalloproteins get the correct metal? Nat. Rev. Microbiol. 7, 25-35. doi: 10.1038/nrmicro2057
Conflict of Interest Statement: The authors declare that the research was conducted in the absence of any commercial or financial relationships that could be construed as a potential conflict of interest.

Copyright $\odot 2015$ Manzoor, Shafeeq, Afzal and Kuipers. This is an open-access article distributed under the terms of the Creative Commons Attribution License (CC BY). The use, distribution or reproduction in other forums is permitted, provided the original author(s) or licensor are credited and that the original publication in this journal is cited, in accordance with accepted academic practice. No use, distribution or reproduction is permitted which does not comply with these terms. 